http://doi.org/10.35784/iapgos.2430

\title{
METHODS FOR ASSESSMENT AND FORECASTING OF ELECTROMAGNETIC RADIATION LEVELS IN URBAN ENVIRONMENTS
}

\author{
Denys Bakhtiiarov, Oleksandr Lavrynenko, Nataliia Lishchynovska, Ivan Basiuk, Tetiana Prykhodko \\ National Aviation University, Kiev, Ukraine
}

Abstract. Methods for synthesis a structural diagram of the processes for detecting and locating technical information leakage channels are analysed. Software for defining a controlled room zone was also presented. A proprietary approach to search the electromagnetic environment under radio interference has been developed to detect devices for unauthorized control of acoustic information using microphones and tran smission of this information using a radio channel.

Keywords: side electromagnetic radiation, controlled zone, radio wave propagation, electromagnetic environment monitoring

\section{METODY OCENY I PROGNOZOWANIA POZIOMÓW PROMIENIOWANIA ELEKTROMAGNETYCZNEGO W ŚRODOWISKACH MIEJSKICH}

Streszczenie. Przedstawiono metody syntezy schematu strukturalnego procesów wykrywania i lokalizacji technicznych kanałów wycieku informacji. Przedstawiono także oprogramowanie do definiowania kontrolowanej strefy pomieszczenia. Opracowano autorskie podejście do przeszukiwania środowiska elektromagnetycznego $w$ warunkach zakłóceń radiowych, $w$ celu wykrywania urzadzeń stużacych do niedozwolonej kontroli informacji akustycznej za pomoca mikrofonów i transmisji tej informacji z wykorzystaniem kanału radiowego.

Słowa kluczowe: niepożądane promieniowanie elektromagnetyczne, strefa kontrolowana, propagacja fal radiowych, monitoring środowiska elektromagnetycznego

\section{Introduction}

One of the areas of monitoring the electromagnetic environment is the search and detection of specially organized and potential radio channels for information leakage $[9,12]$.

The duration of the search process and the reliability of the received information depend on the completeness of solving tasks by search equipment. The completeness and speed of their implementation, the effectiveness of the search engine, the reliability of the information obtained and the probability of decision-making depend on the structure of the search engine and the characteristics of the tools used in it $[6,8]$.

\section{Detection of technical leakage channels}

Detection of technical leakage channels is a complex multi-stage process, which in a simplified form can be represented as a set of a number of stages presented in Fig. 1.

And the Stage I involves the analysis of the current load range and the accumulation of data on the frequencies, levels and nature of electromagnetic radiation in the operating frequency range with the binding of data to the receiving location. "Known" radiation means a set of data accumulated over a certain period of time on the loading of the range, obtained by the results of the current control. It is assumed that there are no dangerous signals, which is achieved, for example, by the gradual accumulation of "known" radiation with careful verification of each of the radiation.

The list of "unknowns" (Stage II) includes data on radiation, the set of parameters which meet the specified search criteria. The use of a "reference" antenna involves the presence in the search engine of an antenna switch that provides alternate connection of one of the receiving (in a dedicated room) antennas and a "reference" antenna that is outside the controlled area, but provides reliable reception of all external signals.

Stage III involves testing, which gives a certain effect both when detecting radio microphones without closing (radiation in a dedicated room specially synthesized acoustic signals) and when conducting special studies on IEMRI by appropriate modulation of informative radiation parameters [2].

To perform Stage IV, it is necessary to compare the maximum (from the outputs of antennas in the controlled area) components of the spectrum with the levels of the corresponding components previously accumulated in the selected room "known" electromagnetic radiation (in the absence of radiation) and the limit level comparison, the decision is made on the presence (absence) of "unknown" radiation in the controlled area.

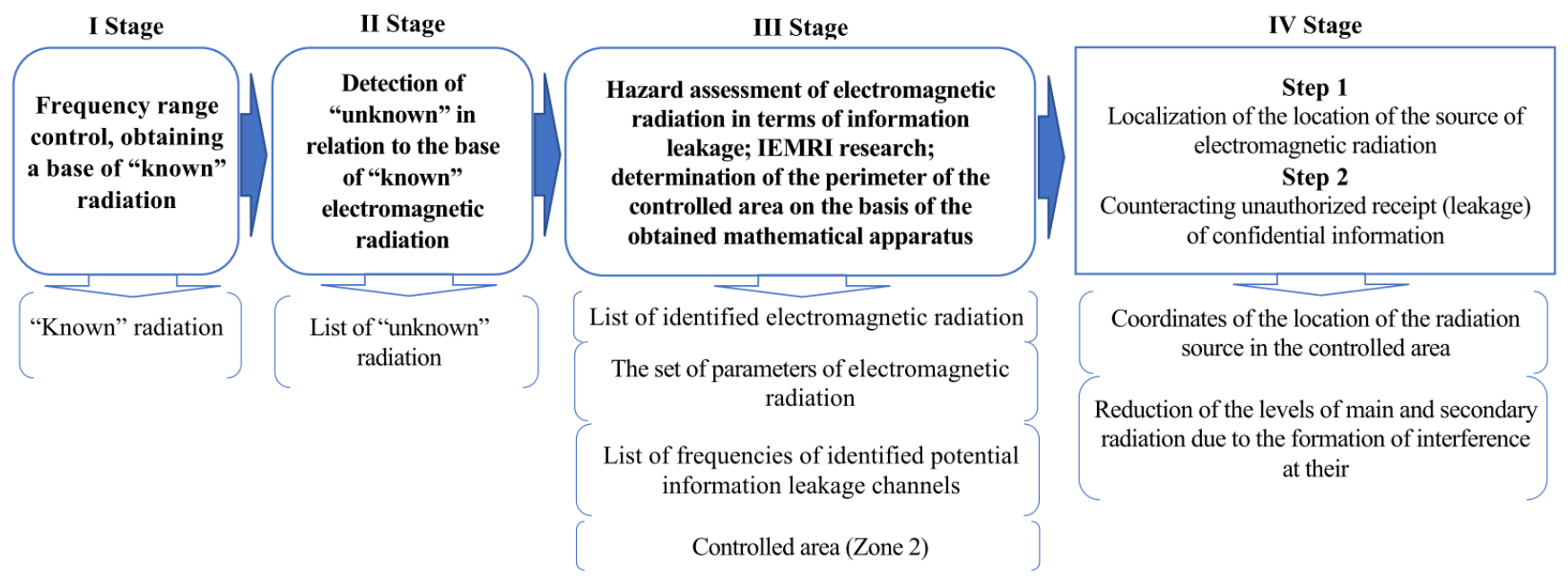

Fig. 1. The main stages of the process of identifying technical channels of information leakage 
The coordinates for monitoring the electromagnetic environment are selected from the set of spectral samples $X_{R}(J, n)$ averaged over $\mathrm{R}$ realizations of the energy spectrum.

$$
X_{R}(j, n)=\frac{1}{R} \times \sum_{r=1}^{R}\left|c_{(r)}(n)\right|^{2}
$$

where $j$ is the number of the antenna connected to the input of the monitoring equipment.

The average power of a random process $U_{m}(t)$, represented in the frequency domain by a set of values of $X_{R}(j, n)$ numbers from $\mathrm{n}_{\min }$ to $\mathrm{n}_{\max }$, is proportional to the sum of these samples [4]:

$$
\hat{P}_{j, m}=10 \lg \left(\sum_{n=n_{\min }}^{n_{\max }} X_{R}(j, n)\right)+\mu,
$$

where $\mu$ - correction factor, which is determined by calibration of the antenna and equipment of the used channel for monitoring the electromagnetic environment (MEE).

The proposed structure of the search engine, which implements this algorithm and provides increased integrated sensitivity and maximum speed, contains: a set of wide-range antennas, one of which ("reference") is made outside the dedicated room; controlled antenna switch; frequency-controlled receiving path with IF bandwidth; analog-to-digital processing device based on fast Fourier transform; control device with a variable structure, which is determined by the proposed software.

Improving the efficiency of the use of MEE equipment in this method is provided by: the use of panoramic analysis based on FFT; reducing the amount of data processed when using a database of "known" electromagnetic radiation or signals from the output of the "reference" antenna.

This method is based on the known position of electrodynamics about the different nature of changes in the electromagnetic field strength in the near and far zones $[1,4,5,10,11]$. The components of the electric field vector emitted by the electric dipole $p$ in spherical coordinates are determined by the expressions:

$$
\left\{\begin{array}{l}
E_{r}=\frac{1}{2 \pi \varepsilon}\left(\frac{1}{r^{3}}-\frac{i k}{r^{2}}\right) \cos \Theta|\vec{p}| \exp [-i \omega t] \\
E_{\Theta}=\frac{1}{4 \pi \varepsilon}\left(\frac{1}{r^{3}}-\frac{i k}{r^{2}}-\frac{k^{2}}{r}\right) \sin \Theta|\vec{p}| \exp [-i \omega t] \\
E_{\varphi}=0
\end{array}\right.
$$

where $r, \Theta, \varphi-$ spherical coordinates, $E_{r}, E_{\theta}, E_{\varphi}-$ components of the electric field in spherical coordinates, $\varepsilon, \mu$ - electric and magnetic permeability of free medium, $\omega-$ angular frequency of radiation.

The dipole moment is related to the radiated power $W$ by the ratio:

$$
W=\frac{\omega^{4}}{12 \pi} \mu \sqrt{\varepsilon \mu}|\vec{p}|^{2},
$$

The module of electric field strength is determined by the expression [11]:

$$
\begin{aligned}
& |\vec{E}|=\sqrt{\frac{12 \pi W}{\mu \sqrt{\varepsilon \mu \omega^{4}}}} \cdot \\
& \cdot\left(\frac{1}{(2 \pi \varepsilon)^{2}}\left(\frac{1}{r^{6}}+\frac{k^{2}}{r^{4}}\right) \cos ^{2} \Theta+\right. \\
& \left.+\frac{1}{(4 \pi \varepsilon)^{2}}\left(\left(\frac{1}{r^{3}}+\frac{k^{2}}{r}\right)^{2}+\frac{k^{2}}{r^{4}}\right) \sin ^{2} \Theta\right)^{\frac{1}{2}}
\end{aligned}
$$

The maximum modulus of electric field strength in all possible directions $\Theta$, for a given $r$ is determined by the expression [11]:

$$
\begin{aligned}
& E_{\max }(r)=\sqrt{\frac{12 \pi W}{\mu \sqrt{\varepsilon \mu \omega^{4}}}} \cdot \\
& \cdot\left(\operatorname { m a x } \left\{\frac{1}{(2 \pi \varepsilon)^{2}}\left(\frac{1}{r^{6}}+\frac{k^{2}}{r^{4}}\right) \cos ^{2} \Theta+,\right.\right. \\
& \left.\left.+\frac{1}{(4 \pi \varepsilon)^{2}}\left(\left(\frac{1}{r^{3}}+\frac{k^{2}}{r}\right)^{2}+\frac{k^{2}}{r^{4}}\right)\right\}\right)^{\frac{1}{2}}
\end{aligned}
$$

In Fig. 2 shows the dependences of the maximum value of the modulus of electric field strength $E_{\max }$, generated by relatively low-power $(100 \mu \mathrm{W}$ and $1 \mathrm{~mW})$ EMR sources with frequencies of 30 and $300 \mathrm{MHz}$ in a dedicated room at distances $\mathrm{R}$ from 1 to $10 \mathrm{~m}(100 \mathrm{~W})$ sources of electromagnetic radiation, such as radio stations, $3 \mathrm{~km}$ away from the allocated room.

Analysis of the nature of the change in the curves shows that in the near $(1 \ldots 8 \mathrm{~m})$ zone the level of radiation from low-power sources, as expected, exceeds the level of powerful but remote sources. To realize the possibility of detecting low-power radio microphones in a complex interfering electromagnetic environment and increase the efficiency of the search system in a dedicated room are several (2 ... 4) antennas with quasiisotropic patterns. They are installed in such a way that any placement of the radio microphone, its distance to the antenna will be 1 ... 5 meters, which corresponds to the "near" reception area.

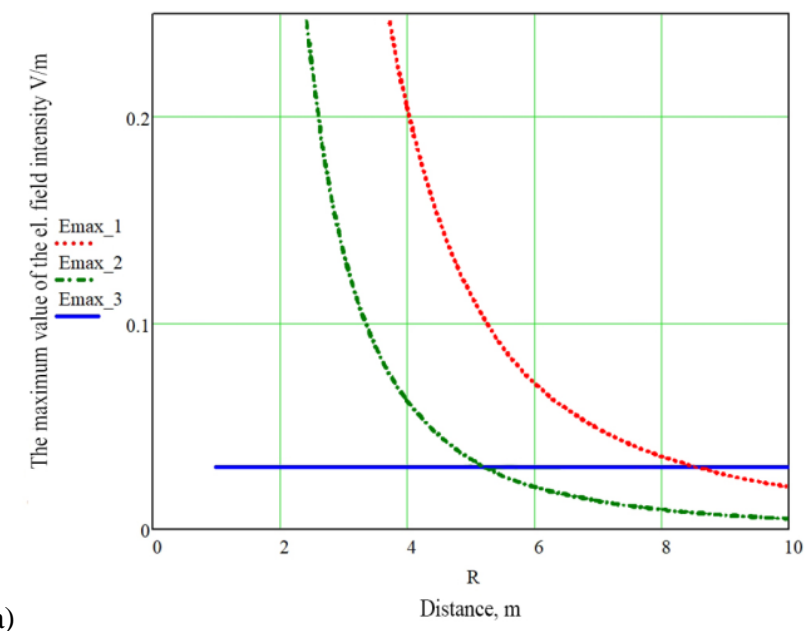

(a)

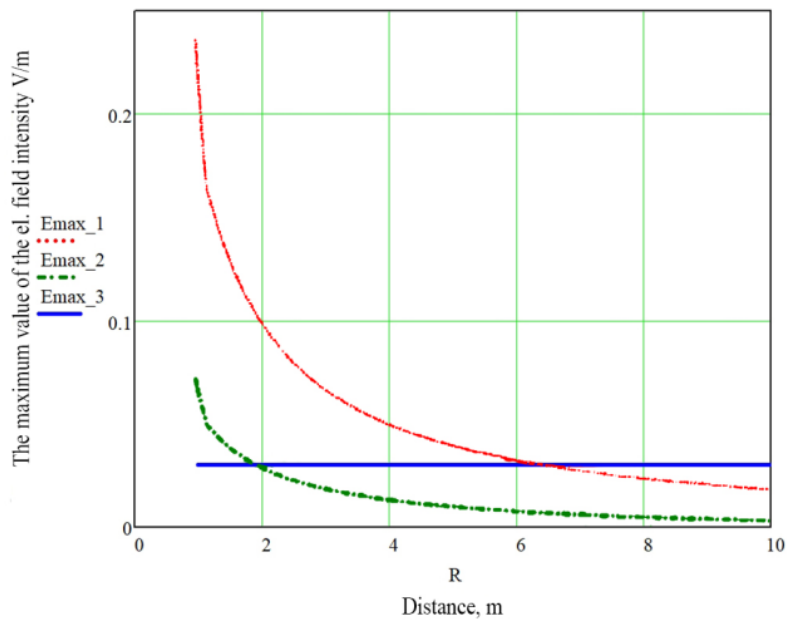

Fig. 2. Dependence of $E$ max on the distance to the radiation source at the frequency (a) $30 \mathrm{MHz}$ with values of capacity of $1 \mathrm{~mW}\left(e_{\text {max }_{-}}\right), 100 \mathrm{mkW}\left(E_{\text {max }_{-}}\right), 100 \mathrm{~W}$ $\left(E_{\max _{3}}\right) ;\left(\right.$ b) $300 \mathrm{MHz}$ with values of capacity of $1 \mathrm{~mW}\left(e_{\left.\max _{-}\right)}\right), 100 \mathrm{mkW}\left(E_{\max _{2} 2}\right)$, $100 \mathrm{~W}\left(E_{\max \_}\right)$ 
This method makes it possible to select the antenna whose output signal has the highest level. This achieves the following possibilities: to select the radiation of the RU against the background of radiation of regular radios; compensate for the non-uniformity of the radiation pattern of quasi-isotropic antennas in different spatial sectors [7].

The ability to connect to one of the inputs of the switch external ("reference") antenna significantly increases the probability of distinguishing between external and internal radiation sources in a complex electromagnetic environment, increases the speed of finding new signals.

\section{Procedure for detecting sources of "unknown" electromagnetic radiation}

The developed approach and the recommended procedure for detecting sources of "unknown" electromagnetic radiation, taking into account the determined and random deviations of the parameters of the electromagnetic field in the short circuit consists of the following steps:

1) The radio receiving device is tuned to a frequency range equal to the band number $\mathrm{q}$ of the operating range $\mathrm{RD}$,

$$
\mathrm{q}=1,2, \ldots, Q, Q=\frac{R D}{\Delta F} .
$$

2) The antenna switch connects to the input of the device MEE "reference" antenna with the number $j(j=1)$.

3) Readout observed energy spectrum of the input random process based on $\hat{\sigma}_{\text {clarif }}^{2}=\frac{N}{N_{p}-N_{c}} \times \sum_{n \notin \Theta_{c}} X_{n}$, calculated estimation of noise intensity.

4) Narrowband signals in the frequency band are detected $\Delta F(q)$ and all components that have exceeded the threshold value are stored.

5) The antenna switch connects to the input of the device MEE antenna with a number $j=2, \ldots, J$ after which the steps are performed in accordance with steps 3,4 .

6) For each of the detected signals $u_{m}(j, t), j=2, \ldots, J$ the number $j$ and the average power for which the $\hat{P}_{j, m}$ maximum is determined, as well as $\hat{P}_{1, m}$ for the reference antenna $(j=1)$.

7) For each of the detected signals, an estimate of the difference in the observed intensity is calculated $\Delta P_{\text {observ }}$ according to the rule: $\Delta P_{\text {observ }}=10 \lg \left(\frac{\hat{P}_{j, m}}{\hat{P}_{1, m}}\right)+\left(\mu_{c}-\mu_{o}\right)$, where $j=2, \ldots, J$ with recalculation of correction factors $\mu_{c}$ and $\mu_{o}$ according to the antenna parameters in the short circuit ("signal") and "reference".

8) Determine the class of the source of electromagnetic radiation $\varsigma_{m}$ in accordance with the rule:

$$
\varsigma_{m}=\left\{\begin{array}{l}
\rho_{s c}, \text { if } \Delta P_{o b s e r v}>\Delta P_{t h r 2}, \\
\text { notspecified }, \text { if } \Delta P_{t h r 1}<\Delta P_{o b s e r v}<\Delta P_{t h r 2}, \\
\rho_{\text {ext }}, \text { if } \Delta P_{o b s e r v} \leq \Delta P_{t h r 1}
\end{array}\right.
$$

where $\rho_{s c}$-combines sources belonging to the short circuit, and $\rho_{e x t}-$ remote radiation sources.

9) Further procedure is repeated for all parts of the operating range, an action on items $1-9$ for $q=2$ and so on.

The thresholds used $\Delta P_{t h r 1}$ and $\Delta P_{t h r 2}$ can be adjusted in each case taking into account the properties of the control area and the location of the receiving antennas. In addition, these thresholds may be different for different parts of the spectrum according to the actual parameters of the electromagnetic environment. Based on the above, it can be concluded that the identified structural patterns of distribution of the electromagnetic field inside the premises can be implemented to improve the use of radio devices and telecommunications to monitor the electromagnetic environment, search for devices for covert removal of confidential information and technical leakage channels.

\section{Conclusions}

As a result of the conducted scientific researches on the problems considered in the third section of the dissertation work the following most important scientific results are received:

1) Scientific methods of synthesis of multi-stage process of detection of technical channels of information leakage are substantiated, which includes stages: obtaining "known" EMR (I), detection of "unknown" EMR (II), identification and risk assessment of EMR and IEMRI (III) and construction of controlled perimeter zone, localization of the location of the detected source of electromagnetic radiation and counteraction to the removal (leakage) of information (IV). The results of research: "known" radiation (I), a list of "unknown" radiation (II), lists of identified EMR, parameters of digital radio signals and frequencies of detected potential leakage channels (III), coordinates of the location of the source of electromagnetic radiation in the selected room at the frequencies of the identified EMR sources and the reduction of the level of spurious emissions of the tested technical means (IV).

2) An original approach, algorithm and methods of synthesis of single - channel hardware and software search and detection of technical channels of information leakage have been developed, which solve the problem of detecting unauthorized radio microphones installed in a confined space and increase detection speed in radio interference conditions used any type of modulation.

\section{References}

[1] Atroshenko L. M. et al.: The field distribution in the near field of waveguide and horn radiators. 14 Russian Symposium with International Participation "Millimeter waves in medicine and biology" 2007, 2-5.

[2] Bakhtiiarov D. I., Konakhovych G. F., Lavrynenko O. Y.: An Approach to Modernization of the Hat and COST 231 Model for Improvement of Electromagnetic Compatibility in Premises for Navigation and Motion Control Equipment. IEEE 5th International Conference on Methods and Systems of Navigation and Motion Control (MSNMC), Kiev, 2018, 271-274 [http://doi.org/10.1109/MSNMC.2018.8576260].

[3] Bakhtiiarov D.: Evaluation of energy availability of means to communicate with UAVs in conditions of radioelectronic countermeasures by the enemy. Information Technology and Security 4/2016, 114-130.

[4] Gorobets N. N., Ovsyannikova Y. Y.: Wave processes in the near-field zone of large aperture antenna. 9th International Kharkiv Symposium on Physics and Engineering of Microwaves, Millimeter and Submillimeter Waves (MSMW), Kharkiv, 2016, 1-3 [http://doi.org/10.1109/MSMW.2016.7538065].

[5] Gorobets N. N. et al.: Near-field plane distribution of rectangular waveguide excited by dominant and higher-order modes. MSMW'07 Symposium Proceedings 2007, 687-689.

[6] Kazakov G. N. et al.: Radio Monitoring of Wireless Networks Using LoRa Data Transmission Technology. 2020 Systems of Signals Generating and Processing in the Field of on Board Communications, Moscow, 2020, 1-5.

[7] Kozliuk I. O. et al.: Problems of unauthorized interference to the work of uav and methods of its solving. Science-Based Technologies 30(2)/2016, 206-211.

[8] Shen X. et al.: Dynamic threshold based target signal cooperative extraction method for high frequency electromagnetic environment measurement. 3rd IEEE International Conference on Control Science and Systems Engineering (ICCSSE), Beijing, 2017, 552-555 [http://doi.org/10.1109/CCSSE.2017.8087993].

[9] Shen X. et al.: Green Hierarchical Radio-over-Fiber Distributed Antenna System Based Wireless Sensor Network for Spectrum Monitoring. IEEE International Conference on Computer and Information Technology, Xi'an, 2014, 880-883 [http://doi.org/10.1109/CIT.2014.105]

[10] Vedenkin D. A., Potapova O. V., Sedelnikov Yu. Ye.: Antennas focused in the near radiated field zone. Features and technical application. International Conference on Antenna Theory and Techniques 2013, 560-565.

[11] Yurtsev O. A., Naumovich N. M.: Field research in near zone of antennas carried out at Belarusian state University of informatics and radioelectronics. International Conference on Antenna Theory and Techniques 2013, 566-571.

[12] Zhong L.: Monitoring Function Design of Radio Monitoring Management System Based on C/S Architecture. 10th International Conference on Information Technology in Medicine and Education (ITME), Qingdao, China, 2019, 424-428 [http://doi.org/10.1109/ITME.2019.00101]. 
M.Sc. Denys Bakhtiiarov

e-mail: bakhtiiaroff@tks.nau.edu.ua

Position: graduate student of National Aviation University. Research interests: information security, information coding. Publications: more than 30 scientific publications.

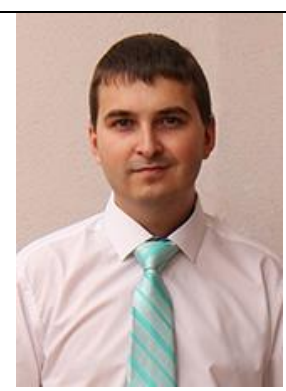

\section{M.Sc. Oleksandr Lavrynenko}

http://orcid.org/0000-0003-3298-46

e-mail: oleksandrlavrynenko@tks.nau.edu.ua

Position: graduate student of National Aviation University. Research interests: signal processing, speech recognition. Publications: more than 30 scientific publications.

http://orcid.org/0000-0002-3285-7565

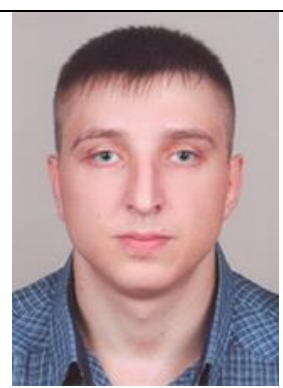

M.Sc. Nataliia Lishchynovska

e-mail: natashalil858@ukr.net

Position: graduate assistant of the Department of Information Security Means. Research interests: method for the synthesis of high-quality resonators. Publications: 13 scientific publications.

http://orcid.org/0000-0002-1913-8419

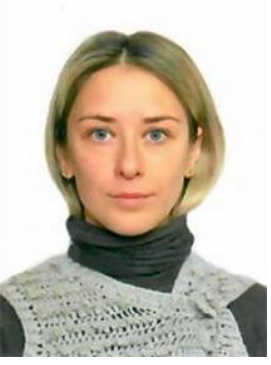

M.Sc. Ivan Basiuk

e-mail: basya2000@gmail.com

Position: Senior Devops Engineer, Globallogic LTd., Kyiv, UA

Publications: more than 20 scientific publications.

http://orcid.org/0000-0002-2666-1136

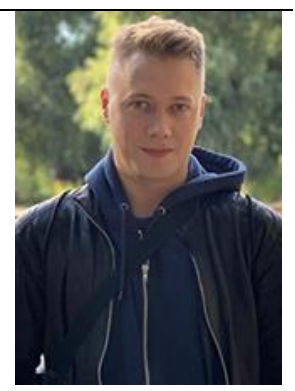

M.Sc. Tetiana Prykhodko

e-mail: tata@mirohost.net

Position: Head of Support Department, Internet Invest, Ltd., Kyiv, UA

Publications: more than 20 scientific publications.

http://orcid.org/0000-0001-6909-7697

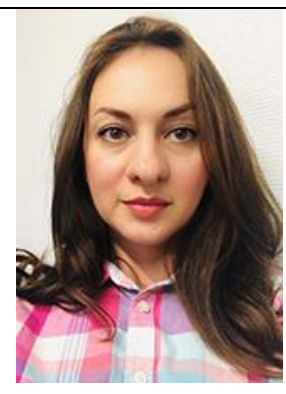

otrzymano/received:14.12.2020

przyjęto do druku/accepted: 15.03 .2021 